\title{
PENERAPAN LOAD BALANCING PADA ROUTER PFSENSE BERBASIS FREE BSD
}

\author{
Arif Rahman Hakim \\ Teknik Informatika Universitas Putera Batam \\ Jl. R. Soeprapto - Muka Kuning - Batam \\ Arif.ibn06@gmail.com \\ Submitted: 10-10-2017, Reviewed: 26-10-2017, Accepted 03-11-2017 \\ http://dx.doi.org/10.22202/jei.2017.v4i1.2534
}

\begin{abstract}
ABSTRAK
Pada zaman teknologi saat ini, arus informasi bergulir dengan sangat deras. Dimana kecepatan dalam pengiriman data menjadi hal yang sangat penting. Teknologi jaringan sering digunakan dalam melakukan pengiriman data dari satu komputer ke komputer lainnya. Dalam lalu-lintas suatu jaringan, Internet Service Provider mempunyai peran yang sangat penting, karena penyedia layanan jasa internet untuk kliennya guna mendapatkan informasi. sebuah ISP mengalami gangguan internal, tentunya klien sama sekali tidak dapat mengakses internet. Untuk itulah dibuat suatu solusi dengan menambahkan ISP yang berbeda. Namun dengan adanya beberapa ISP, bandwidth yang diberikan oleh masing-masing ISP. Sehingga semua bandwidth harus digabungkan menjadi satu agar pembagian bandwidth untuk masing-masing pengguna mendapatkan layanan yang sama. Maka diperlukan suatu teknik yaitu load balancing. load balancing dapat menggabungkan beberapa jalur akses internet yang kemudian bekerja bersama-sama tampak seperti satu internet yang terintegrasi. Pfsense merupakan distro linux turunan free bsd, disesuaikan untuk digunakan sebagai firewall dan router. Pfsense tampilan sederhana dengan web gui administrator memudahkan kita mengoperasikanya.
\end{abstract}

Kata kunci: Load Balancing, Pfsense, Jaringan

\section{ABSTRACT}

In today's technological age, information flows very swiftly. Where speed in data delivery becomes very important thing. Network technology is often used in sending data from one computer to another. In the traffic of a network, Internet Service Providers have a very important role, because the internet service provider for its clients to obtain information. an ISP experiencing internal disturbance, of course the client can not access the internet at all. That's why a solution is created by adding different ISPs. But with the presence of multiple ISPS, the bandwidth provided by each ISP. So all the bandwidth must be combined into one so that the sharing of bandwidth for each user get the same service. Then required a technique that is load balancing. 
load balancing can incorporate multiple internet access points that then work together looking like an integrated internet. Pfsense is a linux distro of free bsd, customized for use as a firewall and router. Pfsense simple view with web gui administrator makes it easy for us to operate it.

Keywords : Load Balancing, Pfsense,Network

\section{PENDAHULUAN}

Zaman ini informasi menjadi kebutuhan yang penting bagi masyarakat. Informasi dituntut untuk update dan beberapa sektor kehidupan tidak bisa menerima adanya kegagalan atau keterlambatan akibat adanya gangguan pada sistem. Dapat dicontohkan pada sektor bisnis saham yang sedikit saja terjadi keterlambatan pada sistem komputerisasinya maka akan menanggung kerugian yang sangat besar.

Internet dari kata Interconnection Networking dapat diartikan dengan jaringan yang selalu berhubungan, semakin pesat serta banyak muncul beberapa teknologi untuk menggunakan internet. Kita bisa menikmati berbagai macam fasilitas jika ingin mencari informasi tentang sesuatu. Untuk tersambung pengguna harus menggunakan layanan khusus yang disebut ISP (Internet Service Provider). Begitu tersambung ke server ISP, user bisa mengakses jaringan internet. Permasalahan yang sering terjadi koneksi internet tersendat bahkan terputus, padahal kita sebagai pengguna menginginkan koneksi internet yang lancar.
Oleh karena itu timbul solusi, yaitu menggunakan dua ISP dan menjadikan Pfsense tersebut sebagai load balancer. Dan diharapkan Pfsense dapat mengoptimalkan pembagian bandwidth pada setiap client yang ingin mengakses internet, Pfsense merupakan distro linux turunan free bsd, disesuaikan untuk digunakan sebagai firewall dan router(Journal, 2012). Pfsense tampilan sederhana dengan web gui administrator memudahkan kita mengoprasikanya.

\section{TINJAUAN PUSTAKA}

\subsection{Load Balancing}

Load balancing merupakan teknik dalam mendistribusikan beban trafik pada dua atau lebih jalur koneksi yang terhubung secara seimbang, dimana trafik dapat berjalan secara optimal, dengan memaksimalkan throughput memperkecil waktu tanggap dan menghindari overload pada salah satu jalur Koneksi, Load balancing merupakan salah satu mekanisme untuk membagi beban komputasi ke beberapa server (Setyawan, 2014).

Dengan banyak link yang dimiliki maka mengoptimalisasi sumber daya, throughput, atau response time, dimana akan semakin baik karena lebih dari satu 
link yang bisa menjadi backup pada saat salah satu link koneksi down dan menjadi cepat pada saat network normal memiliki realibilitas tinggi yang memerlukan $100 \%$ koneksi, koneksi dua jalur internet ke banyak komputer dalam menjaga keseimbangan beban, seperti ditunjukan pada Gambar 2.1.

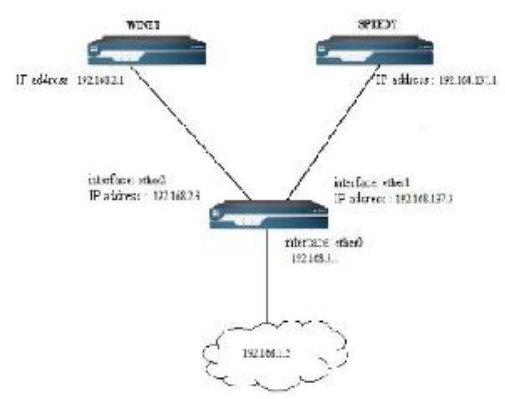

Gambar 2.1 Load Balancing.

\subsection{Routing}

Routing suatu aturan atau bahasa yang digunakan oleh perangkat elektronik untuk berkomunikasi maupun saling berbagi informasi (Internetindo, 2015) digunakan untuk menentukan jalur yang akan dilewati paket dari satu device ke device yang berada di dalam jaringan, Routing hanya dapat dilakukan apabila network menggunakan router (Wardoyo, Ryadi, \& Fahrizal, 2014). Ada beberapa hal yang mesti diketahui, sebelum kita membuat routing di antaranya :

\section{Routing Host}

Routing yang dilakukan oleh host cukup sederhana. Jika host tujuan terletak di jaringan yang sama atau terhubung langsung.

2. Network Routing routing merupakan konsekuensi dari internetworking. Semakin kompleks topologi dan konfigurasi dari network, semakin penting teknik dan sistem routing yang handal untuk di implementasikan dalam network.

\subsection{Nat}

Network AddressTranslation atau yang lebih biasa disebut dengan NATadalah suatu metode untuk menghubungkan lebih dari satu komputer ke jaringan internetdengan menggunakan satu alamat IP.

Ada 3 jenis utama dari NAT:

1. SourceNAT

2. Destination NAT

3. Bidirectional NAT

\subsection{Pfsense}

FreeBSD merupakan suatu sistem operasi yang bekerja layaknya seperti UNIX akan tetapi bukan turunan UNIX. dikembangkan oleh Berkeley Software Distribution pada tahun 1993.

PfSense merupakan FreeBSD berbasis sistem operasi, pfSense dirancang sebagai firewall dan router. Selain menjadi kuat, fleksibel firewall dan routing platform, ini meliputi daftar panjang fitur terkait dan sistem paket yang 
memungkinkan upgrade lebih lanjut tanpa menambah gembung dan potensi kerentanan keamanan ke basis distribusi.

\section{METODE PENELITIAN}

\subsection{Kerangka Kerja}

Kerangka kerja merupakan langkahlangkah atau tahap untuk pelaksanaan membangun sistem yang akan dirancang. Kerangka kerja :

1. Setup konfigurasi pfSense.

2. Pengaplikasian fitur-fitur yang ada pada PfSense.

\section{2 jaringan Yang Akan Dirancang}

Jaringan yang dirancang dapat dilihat pada gambar 3.1.

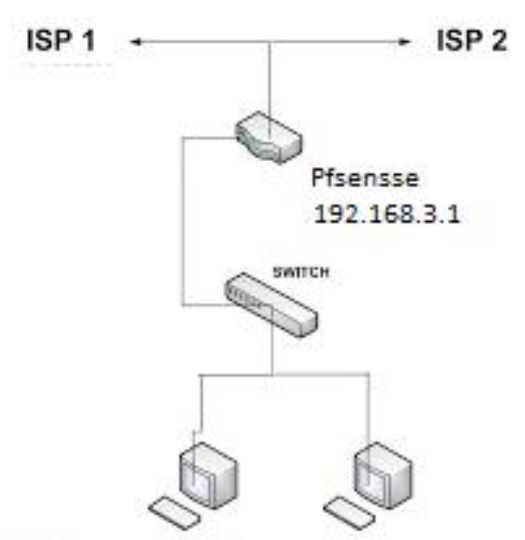

Gambar 3.1 jaringan yang dirancang

\section{HASIL DAN PEMBAHASAN}

\subsection{Konfigurasi Pada Pfsense}

Berikut adalah langkah-langkah mengkonfigurasi load balancing di system operasi pfsense:

1. Monitor IP
Monitor ip digunakan untuk melakukan monitoring status network down atau tidak. System->Routing

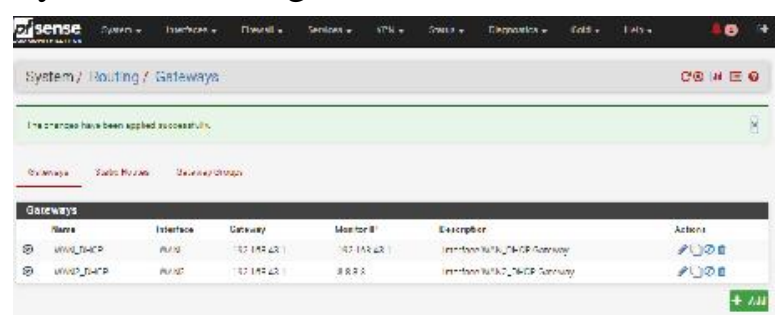

Gambar 3.1 Monitor ip

Kemudian pilih tombol edit,monitor ip diisikan dengan ip.

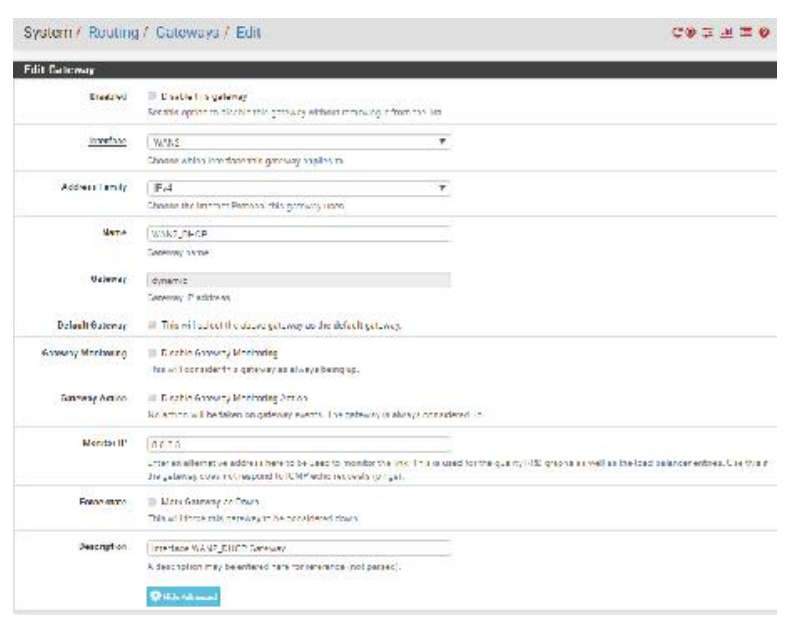

Gambar 3.2 Edit Gateway

2. Konfigurasi Gateway Group.

Setelah mendefinisikan monitor ip,langkah selanjutnya adalah membuat gateway group.System->Routing ->Gateway Group. pilih + untuk membuat gateway group. 
Pilih tombol edit, pada group pertama isikan dengan nama W1balanceW2,dan untuk Gateway Priority Wan1=tier1 dan Wan2=tier1, trigger level=high latency.

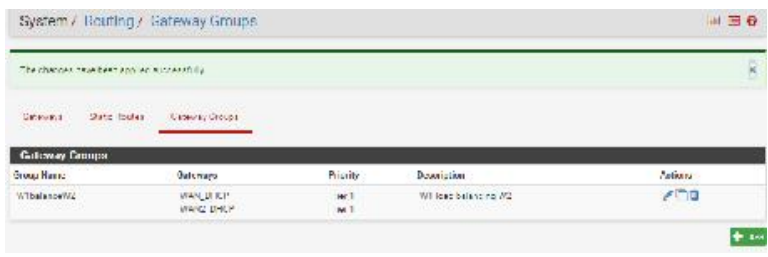

Gambar 3.3 Gateway group

3. Konfigurasi Firewall Rules

Tambahkan Rule Firewall melalui menu Firewall ->Rules->LAN pilih edit.

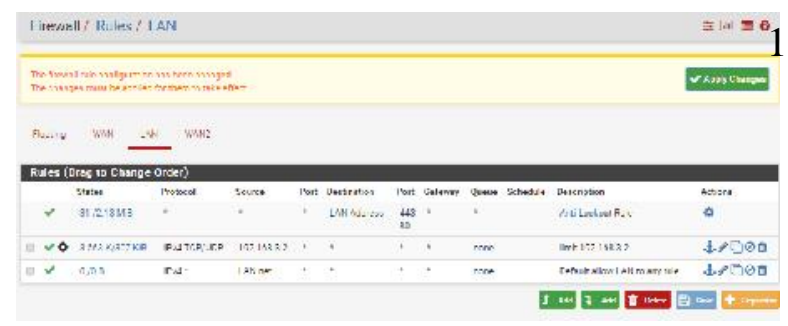

Gambar 3.4 Konfigurasi Firewall Rules

pada bagian advanced features -> gateway. rubah menjadi nama gatewayGroup yang sebelumnya telah kita buat.

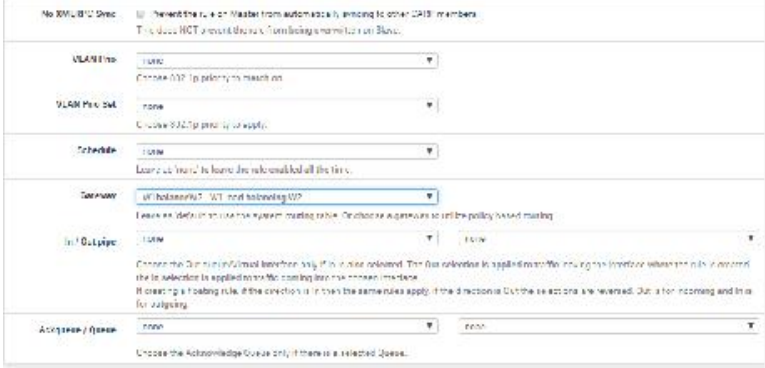

Gambar 3.4 advanced features

4. Real time status graph

cek di Status->Traffic Graph pilih interface yang ingin di monitor.

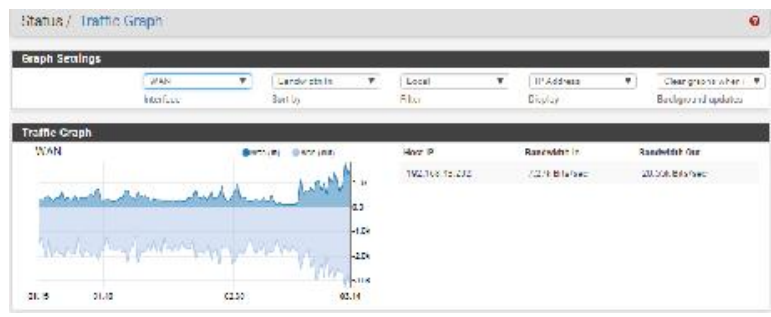

Gambar3.5 Real time status graph

\section{KESIMPULAN DAN SARAN}

\subsection{KESIMPULAN}

Berdasarkan hasil penelitian dan pembahasan, maka penelitian ini dapat disimpulkan sebagai berikut:

1. Mengimplementasikan load balancing mempunyai lebih dari satu ISP (Internet Service Provider). load balancing akan bekerja dengan sendirinya oleh perangkat tersebut. Jika salah satu ISP mengalami gangguan, maka koneksi akan tersambung pada ISP yang lain.

2. Menggabungkan bandwidth dari dua ISP dan mengkonfigurasikan IP Address dari masing-masing ISP. Setelah dikonfigurasi, maka perangkat tersebut akan secara otomatis menggabungkan bandwidth yang ada dari dua ISP tersebut.

3. penggabungan bandwidth akan memberikan manfaat pada efektivitas bekerja yang selalu terhubung ke internet. 


\subsection{SARAN}

Terdapat beberapa saran untuk pengembangan lebih lanjut dari penelitian ini sebagai berikut:

1. Penggunaan load balancing ini dapat dikembangkan lagi dari segi fiturfitur berguna yang masih banyak lagi.

2. Pertimbangan terhadap load balancing apakah dapat menciptakan sebuah efiensi atau berguna untuk pemakai di lingkungan kerja.

\section{DAFTAR PUSTAKA}

Internetindo, P. T. K. (2015). Perancangan Routing Protocol Di Jaringan, 4(4), 23 28.

Journal, I. (2012). PENERAPAN ROUTER PFSENSE BERBASIS FREE BSD DI WARNET EMAX SRAGEN Agus Sarifin, Bhekti Ratna Timur Astuti. IJNS - Indonesian Journal on Networking and Security, 1(November), 61-66.

Setyawan, R. A. (2014). Analisis Implementasi Load Balancing dengan Metode Source Hash Scheduling pada Protocol, 8(2), 204-208.

Wardoyo, S., Ryadi, T., \& Fahrizal, R. (2014). Analisis Performa File Transport Protocol Pada Perbandingan Metode IPv4 Murni, IPv6 Murni Dan Tunneling 6to4 Berbasis Router Mikrotik. Jurnal Nasional Teknik Elektro, 3(2), 106-117. 